\title{
The contributions of social interdisciplinary practices in problem-based learning medicine course.
}

\author{
MF da Silva, PAD Costa, MCS Fernandes, ACALL Tavares, MN Santana, MAS \\ Margotto \\ College of Medicine, State University of Santa Cruz, Bahia, Brazil
}

\begin{abstract}
Traditional and basic disciplines of medicine schools are rarely invited to participate of interdisciplinary experiences outside the classroom. Although exists vast literature on problem-based learning medicine courses, there are few studies focusing the socialization of students to learn more complex topics. In this paper, the authors revisited the diagnostic of local health based on Charles Maguerez's arch method that enables the collective construction of knowledge, starting with the observation of family health center attributions. Students were encouraged to collaborate with health agents to investigate the causes of illness in the community. Dengue emerged as a main health problem and it was used as central theme. After the students had theorized about main problems, they developed a strategy in order to propose alternatives for a communitarian intervention plan. Then, day-care and healthcare centers, schools, health agents and students of medicine were involved in a multiple educational approach to increase the awareness of community on dengue prevention. The analysis of data reveals that problem-based learning with social insertion helped the students to develop skills and core competences to a more realistic practice of socialized medicine integrated with health service.
\end{abstract}

Keywords: Medicine, problem based learning, health promotion

\section{Introduction}

The Brazil's Unified Health System (SUS) was developed over the last 25 years, shaped by the history and democracy consolidation based on politics, economics, social and cultural transformations. As a cornerstone, the 1988 Constitution was based on the principles of universality, integrality, equity, community participation, political and administrative decentralization of health services (Paim et al. 2011). Health care services are used to be divided into primary, secondary and tertiary levels which organize health demands according to the level of its complexity. More advanced comprehension on health management was achieved by the notion of primary care offered by local arrangements of different health services (Silva, 2011). Then, medicine schools had to face the demands of medical resources according to the reality of a new and up challenging health care system. Although the bases of the SUS encompass the problem-based learning (PBL) and the case studies, medicine schools have chosen different strategies to attend government policies on education and the reality of health services.

The medicine course in State University of Santa Cruz (UESC) offers a regular module as Interdisciplinary Practices of Education, Health Service and Community (IPEHSC). This module was designed up to enable a first approximation and precocious contact of medicine students with community and current health practices on the basis of SUS. Thus IPEHSC has as main objective to provide an innovation in the learning in multi professional health and interdisciplinary teamwork environment, seeking a new health professional to contribute in the construction of the model of health based in primary care.

The model of PBL perfectly meets National Curriculum Guidelines for Undergraduate Medicine (National Council of Education, 2001) which pointed out the demands of egress/medical professional as a generalist, humanist, critical and thinking, based on 
ethical principles, able to work the process of health and disease at different levels of care. It is expected that the students learn promotion, prevention, recovery and rehabilitation of health from the perspective of more comprehensive care, with a subtle sense of social responsibility and committed to citizenship, as promoter of the human wellness.

\section{A case study: Teotônio Vilela village and dengue fever}

The UESC promotes the education on the basis of social requirements at south Bahia, Brazil, where it has social and political range including Ilhéus surroundings (Midlej, 2007). The city of Ilhéus has 184,236 inhabitants, distributed in 1,760,111 km concentrating $84 \%$ of its population in urban areas, whose average income per capita is US\$ 506,00 monthly. Of the total population, 15,685 individuals live in households with inadequate sanitation (Brazilian Institute of Geography and Statistics, 2013). Earlier known in the 1980's as “Gomeira” (because the first residents were known to sell gums in downtown) the Teotônio Vilela village was mainly occupied by rural housing to many workers who had lost their belongings with the collapse of cocoa monoculture in 80's and 90's (Alger \& Caldas, 1994). The territory has physically borders as the Cachoeira river, which establishes a mangrove region, and by a forest preservation area. Despite the attempts of environmental preservation made by public agents, the process of occupation in these areas was not restrained in decades and still persists. Typical geographic and demographic phenomena occur discretely within this periphery as the overvaluation of land and homes and verticalisation of the buildings creating peripherals (Lonardoni, 2014). After 30 years, there is a severe lack of sanitation, crescent violence indexes, insufficient pavements and garbage. The health system is sustained at local level by four Family Health Centers (FHC), emerged in 2006, with the aim of facilitating the population's access to health services. The objective of this paper is present the contribution of extramural social interdisciplinary practices in PBL medicine course focusing the social demands of health care service dealing with inequity and different causes of illness.

\section{Material and Methods}

Subjects and ethic implications: The present paper is based on the public databases analysis and IPEHSC on professor's observations of the joint work of medicine students enrolled in and the CHA during one regular academic year. It has no ethical implications, but complies with the Helsinki Declaration on ethical issues (World Medical Association, 2014).

Observing, understanding and collection of data from reality: The first step of the Maguerez's arch method (Prado et al. 2012) is the viewing of a given situation from many angles, which allows the student to extract and identify the problems that exist in the community. It presupposes a conception of cumulative knowledge from the reality in an effort to build an effective understanding, seeking, intervening and modification; students should observe the territory regarding environmental, housing, sanitation, health assistance and other aspects of local reality, such as schools, day-care and social centers, churches, party offices and others social equipments. The health and social National Databases were consulted in this respect aimed to build a local health diagnosis. 
Problems raised and their explanations: The second stage of the method refers to prioritizing the problems encountered, along with the CHA and inhabitants in collective workshop. At that time students should be applied to the Planning and Programming on Local Health - PPLH. By monitoring the work of CHA and contact with the population, national databases on dengue helped to identify as major health problem recurring in the community and also a feasible theme for an intervention plan. Therefore, taking advantage of the imminence of Children's Day Celebration, the medicine students developed recreational and educational project having dengue themed involving the child, parents, and teachers' audience.

Theorizing to solution, intervention planning and monitoring: The third step involves theorizing of the topics. The group was responsible for the literature review and autonomy of study and the development of educational resources. The participation of the CHA and the inhabitants was considered critical and must be performed, also based on the PPLH. In Noah's Ark school, it was showed a video about the life cycle of the Aedes aegypti mosquito that transmits dengue and the game "Right or Wrong on the Prevention of the Dengue Fever" was performed. In addition, sketches were designed to measure, before and after the activity, in order to analyze the level of previous knowledge of children, as well as the learning results of the proposed action. Finally, children were invited to participate in the contest "CHA junior" which task was to eliminate reservoirs of mosquitoes from their homes and more than two neighbors, under supervision of parents and at least one member of Center of Endemic Control. Two weeks later, aided by Endemics Coordinator of the Department of Health Education of City of Ilhéus, the medicine students visited 30 homes of CHA junior contender - to ensure the fulfillment of objectives proposed. To the completion of the project, the community was invited to hold a march against dengue fever involving students of Noah's Ark as well as their parents and community's representatives. Awards to CHA junior were given to participants who had known how to eliminate reservoirs of the mosquitoes.

Statistical analysis: The data analysis was based on a qualitative study consisting of interpretation of 88 reports and 10 individual interviews. It was applied Chi-square test considering as the expected responses the equitable apportionment among all the alternatives compared to the amount of answers observed in reports. Student's t test was applied to compare mean and standard deviation between two groups. The significant level was $5 \%$. Linear correlations among quantitative data were performed observing the goodness of fit $\left(\mathrm{r}^{2}\right)$ and a confidential interval of $95 \%$ and its significance. Data were analyzed by using GraphPad Prism 4.

\section{Results and Discussion}

\section{Diagnostic of local health:}

The first information on 2012 demographic and health indicators were obtained from public databases (Ministry of Health, 2014). The Figure 1a reveals that the city of Ilhéus had worse health indicators when compared to cities of similar size in other Brazilian regions (Nossa Ilhéus Institute Report, 2013). Most bad indicators refer to circulatory and respiratory diseases and also maternal, neonatal and child morbidity and mortality. Certain infectious and parasitic diseases (not shown) are among the major causes of mortality whereas neglected diseases were seen to be very prevalent among children when compared to other similar surveys (Barreto et al. 2007). In addition, by observing 
the CHA surveying the population, students could include other complaints $(n=88)$ regarding diseases among inhabitants of Teotonio Vilela village. Hypertension has been identified as a major problem (27\%), followed by dengue (15\%) diabetes (8\%) and diarrhea (6\%). The rest of inhabitants referred multiple other causes of diseases (14\%) and healthcare services inaccessibility (30\%). Dengue cases were measured by accessing public databases (Ministry of Health, 2014) and it was possible to confirm the high incidence of disease when compared to other cities with similar territory, demography and urban characteristics of Ilhéus (Figure 1b). As it can been seen, the other cities could have adopted successful strategies to prevent dengue spread and better management of the epidemic when compared to Ilhéus.

\section{Dengue prevention: From biology to action:}

The PBL reached the objective to pose medicine students to develop active strategies of learning such as systematic studies, organization, collaboration in workgroup, guidance and leadership, discussion and decisions having dengue as proposed theme. Hence, it was possible to note the development of skills and core competencies to communicate better with child, parents, teachers and community's representatives regarding the strategies to combat mosquitoes, early recognition of symptoms, diagnosis, care and guidance to seek for medical assistance in neighborhood. Through various delivery modes (Figure 2) medicine students were able to elaborate adequate lectures to child less than 7 years old (Figure 2a); also mobilize community to hold a thematic march (Figure 2b) and to create a successful intervention plan to reduce Aedes aegypti reservoirs in the houses. Children having the greatest performance in this goal were awarded with a medal and a certificate of CHA jr (Figure 2c and 2d). The effort of medicine students to achieve the objective of the intervention plan was partially successful, since the number of houses visited by CHA jr were below $(n=30)$ of the minimal estimated (IC 95\%: 63 - 117). It was possible to verify that the CHA jr initiatives were frustrated mostly by security risks involved or neighbour's disapproval. Nevertheless, there was a positive increment in the number of houses without Aedes aegypti reservoirs (Figure 2e). The experience of socialized PBL on health promotion yielded better evaluation of the medicine students, since their grades were significant higher during the social experience of PBL (Figure 2f).

\section{Contribution of social interdisciplinary practices in $P B L$}

It was possible to note an achievement in the PBL used in a medicine course to study social determination of health and disease in a community living in inequity. The results presented herein showed that the immersion of the students in this context during PBL caused a subtle questioning and a significant learning experience. Students learn beyond the health services and their interrelationships within community, since they learned more about people and the multiple aspects involved with their health, disease and care.

Traditionally, medicine courses have been providing new professionals by subsequently progress of the novices along the curriculum, giving the concepts and knowledge needed to emerge as graduates (Madsen \& Bell, 2012). However, for complex fields of study such as health promotion, there is more theoretical development rather than one that is strictly based on the social praxis (Brosnan, 2013). This raises questions for those teaching such subjects regarding how to connect learning with the social demands on health promotion. 
In Brazil, the teaching of medicine further includes a challenging and contradictory debate since the ideal health workforce - should be composed of professionals skilled, evidence-oriented and well trained and committed to SUS principles - not corresponds to the profile of the professionals who operate the system; this disparity is partly due to general influence of private medical corporations' ideology that public service is considered as just a stable poorly paid job rather than more profitable jobs in private sector or in healthcare companies, consistently more rewarding and strivingly (Almeida-Filho, 2011). Also, the infrastructure, resources and supplies of SUS is widely noted deficient (Siqueira, 2013) historically in northeast of Brazil (Vitoria et al. 2011; Leite, 2011) what contributes to inequity in the access to the services.

In 2006, a university reform took place to reorient the curriculum of medicine and other professions (Ministry of Health, 2013). Further, a plan of massive federal investment intended to double the size of the federation universities (Ministry of Education, 2013) allowing the implementation of undergraduate courses in an interdisciplinary system (Santos \& Almeida-Filho, 2013). As a result, tensions have arisen among Brazilian universities, since there was resistance led by conservatism against the rearrangement of the new ideological basis of teaching. However, the SUS has provoked a replacement of the standard reductionist, disease-oriented, focused on hospital-oriented specialization current vocational education, by another model that is more humanistic, health-oriented, with focus on primary health care and social compromised (AlmeidaFilho, 2011).

The academic education for SUS is causing profound changes in the training for health teamwork; new pedagogical tendencies indicate the need for educational of a critical reflective professional, able to transform their social reality (Madsen \& Bell, 2012). If medical education takes up the challenge of engaging more fully with social science theory, the question of how medicine students will learn about it must be resolved. Although some medical teachers have social science backgrounds, the most come from basic science or clinical disciplines. This fact poses a challenge to fulfill the requirements of a more socialized medicine practice. The incorporation of social learning opportunities, mainly in community, on theoretical perspectives at PBL, is also a positive development for both students and teachers (Bronsnan, 2013). 
Figures

a)

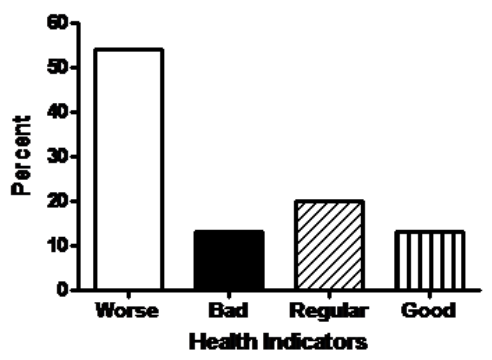

b)

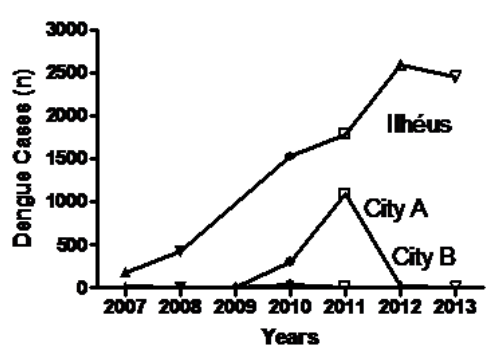

Figure 1. a) Classification of health indicators of Ilhéus, Bahia, Brazil when compared to similar cities. b) Dengue emerged as main disease when compared to other cities with similar demography and territory.

a)

b)

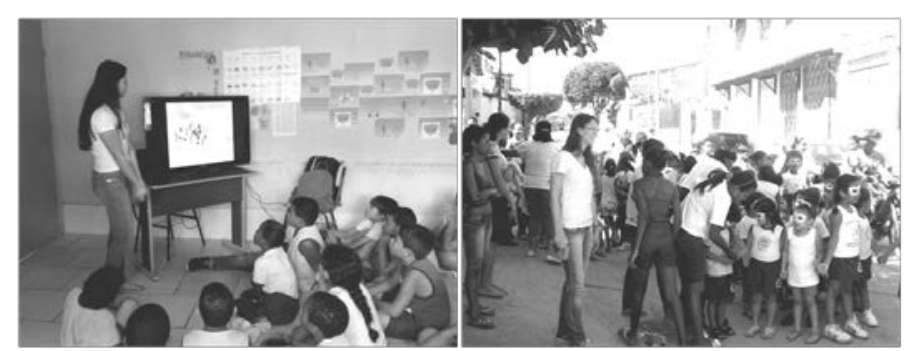

c)

d)

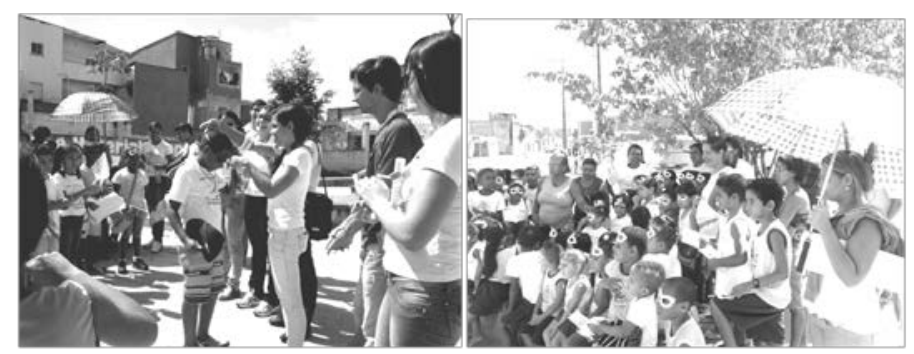

e)

f)

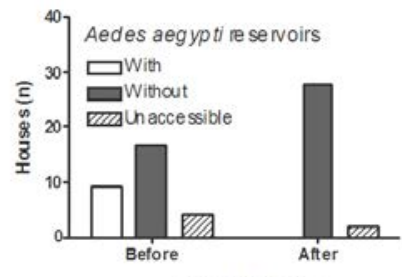

CHA jr visitation

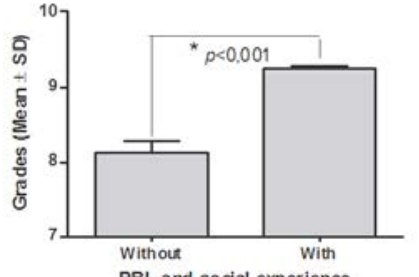

PBL and social experience

Figure 2: Intervention planning developed by medicine student after PBL theme on dengue prevention.

a) Lecture and video on Aedes aegypti cycle and prevention of dengue to Noah's Arch school. b)

Dengue Prevention thematic parade. c) Awards of CHA jr contest. d) Social mobilization of students, parents and community's representatives. e) Results of CHA jr contest in the increase of houses without domestic Aedes aegypti's reservoirs. f) Increase in students' grades was related to PBL with social experience. * $\mathrm{p}<0,001$ Student's t test. 


\section{Conclusions}

Hence, UESC gives an important contribution by adding the social experience to PBL for first-year medicine students. IPEHSC turns to stimulate the dialog between university and healthcare service in order to understand better the demands of public health in south Bahia, Brazil. Thus, through Charles Maguerez Arch method contributed on social interdisciplinary practices in PBL medicine course by following the steps of observing the reality, key-points, theorizing, hypothesis construction and application. The mobility to extramural environment helped the medicine student to develop skills and core competences linked to a more realistic practice of socialized medicine.

\section{References}

Alger K. \& Caldas M. (1994). The declining cocoa economy and the Atlantic forest of southern Bahia, Brazil: conservation attitudes of cocoa planters. Environmentalist, 14, 107-119.

Almeida Filho, N. (2011). Higher education and health care in Brazil. The Lancet, 377(9781),1898- 1900.

Barreto L.M., Genser B., Strina A., Assis A.M.O., Rego R.F., Teles C.A., Prado M.S., Matos S.M.A., Santos D.N., Santos L.A., Cairncross S., Teixeira M.G. (2007). Effect of city-wide sanitation programme on reduction in rate of childhood diarrhoea in northeast Brazil: assessment by two cohort studies. The Lancet, 370 (9599), 1622-1628.

Brazilian Institute of Geography and Statistics (2013). Brasilia, FD: Brazilian Government. Retrieved from: http://www.ibge.gov.br/cidadesat/topwindow.htm1

Brosnan C. (2013). How and why social science theory can contribute to medical education research. Medical Education, 47, 3-17.

Leite, R.M.B. (2011). Fatores de risco para mortalidade materna em área urbana do Nordeste do Brasil. Cad. Saúde Pública, 27(10), 1977-1985.

Lonardoni, F.M. (2012). Informality of house production: rental markets in favelas and challenges for land regularization in Brazil. In: Technologies and innovations for development. J.C. Bolay et al (eds). Springer-Verlag Paris. France 55p.

Madsen W., \& Bell T. (2012). Using health promotion competencies for curriculum development in higher education. Global Health Promotion, 19, 43-49.

Midlej M.M.B.C. (2007). Universidade e região: territorialidade da Universidade Estadual de Santa Cruz - UESC. Rev HISTEDBR On-line, 28, 323 -324.

Ministry of Education. (2013) Brasilia, FD: Brazilian Government. Retrieved from http://portal.mec.gov.br/sesu/arquivos/pdf/diretrizesreuni.pdf

Ministry of Health. (2013). Brasilia, FD: Brazilian Government. Retrieved from: http://dtr2001.saude.gov.br/sas/PORTARIAS/Port2006/GM/GM-648.html

Ministry of Health. (2014). Department of Informatics. Brasilia, FD: Brazilian Government. Retrieved from:

http://tabnet.datasus.gov.br/cgi/deftohtm.exe?sih/cnv/nrba.def

National Council of Education (2001). Resolution 4. Diretrizes Curriculares Nacionais do Curso de Graduação em Medicina. Diário Oficial da União, 11 (1), 38-43. 
Nossa Ilhéus Institute Report. (2013). Indicators for local actions on health. Kairós social development 2012. From:

http://nossailheus.org.br/Fotos/18_ini_indicadores_saude.pdf

Paim J., Travassos C., Almeida C., Bahia L., Macinko J. (2011). The Brazilian health system: history, advances, and challenges. The Lancet, 377(9799), 1778-179.

Prado M.L., Velho M.B., Espíndola D.S., Sobrinho S.H., Backes V.M.S. (2012). Charles Maguerez arch: reflecting methodology strategies on active training for health professionals. Escola Anna Nery, 16(1), 172-177.

Santos B.S., \& Almeida-Filho N (2008). The university of the 21st century: towards a new university. Coimbra: Almedina Press. Retrieve from:

http://www.boaventuradesousasantos.pt/media/A\%20Universidade\%20no\%20Se culo\%20XXI.pdf

Silva S.F. (2011). The organization of regional and integrated healthcare delivery systems: challenges facing Brazil's Unified Health System. Ciência \& Saúde Coletiva, 16(6), 2753-2762.

Siqueira J.E. (2013). SUS (Unified Health System) after 25 years: is there anything to celebrate? O Mundo da Saúde São Paulo, 37(1),56-6.

Victora C.G., Vaughan J.P., Barros F.C., Silva A.C., Elaine T. (2011). Explaining trends in inequities: evidence from Brazilian child health studies. The Lancet, 2000 (356),1093-1098.

World Medical Association. (2014). Declaration of Helsinki - Ethical Principles for Medical Research Involving Human Subjects From:

http://www.wma.net/en/30publications/10policies/b3/ 